\title{
Hypermobility and sports injuries in junior netball players
}

\author{
R Smith, A K Damodaran, S Swaminathan, R Campbell, L Barnsley
}

Br J Sports Med 2005;39:628-631. doi: 10.1136/bjsm.2004.015271

See end of article for authors' affiliations ......................

Correspondence to: Associate Professor Barnsley, Rheumatology Department, Concord Hospital Hospital Road, Concord, NSW 2139, Australia; les.barnsley@ email.cs.nsw.gov.au

Accepted 10 November 2004
Objective: To evaluate the incidence of hypermobility in young female netball players and to determine the relation between hypermobility, previous injuries sustained in netball or other sports, and the use of protective equipment.

Methods: Under 16 year old female netball players from a local suburban netball association were assessed for joint hypermobility using the validated Beighton score (0-9, with higher scores indicating increasing hypermobility). Player profiles and details of sporting injuries, both netball and non-netball, and the use of protective equipment were gathered by means of a self completed questionnaire. Parental and child consent was obtained.

Results: Two hundred netball players were recruited for the study. Twenty one percent of the subjects with a Beighton hypermobility score of $0-2$ had sustained previous netball injuries compared with $37 \%$ with Beighton scores of $3-4$, and $43 \%$ with scores of $5-9$. These differences were significant $(p<0.025)$. Injuries were most common in the ankle (42\%), knee (27\%), and fingers (15\%). Thirty nine players (19\%) wore protective equipment, and within this group $30(77 \%)$ had sustained previous injuries. No association was detected between hypermobile joints and non-netball sporting injuries.

Conclusions: In this study hypermobility was significantly associated with an increased prevalence of injuries in junior netball players. A targeted interventional approach may help to reduce injuries in this susceptible group.
$\mathrm{H}$ ypermobility or generalised joint laxity is defined as a condition in which most of an individual's synovial joints have a range of motion beyond normal limits. ${ }^{1}$ The prevalence of hypermobility in schoolchildren has been estimated to be $13-26.5 \%,{ }^{2-4}$ with a higher prevalence in girls than boys. ${ }^{56}$ Benign joint hypermobility syndrome is traditionally thought of as being a benign condition consisting of generalised joint laxity with non-specific musculoskeletal complaints. The lack of systemic complications differentiates it from some of the other rarer causes of hypermobility such as Ehlers Danlos syndrome and Marfans syndrome. ${ }^{78}$

In some sports, hypermobile joints may be associated with a performance advantage-for example, spin bowlers in cricket, gymnasts, and ballerinas ${ }^{9}$ However, previous studies have revealed an increased incidence of musculoskeletal complaints such as arthralgias, joint subluxations, joint dislocations, and sprains in sportsmen with hypermobile joints. $^{10}$

Netball is the most popular female sport in Australia with an estimated one million players nationwide. ${ }^{11}$ It has been shown to be one of the top five sports associated with sporting injuries in children in Australia, with the ankle joint being one of the most susceptible to injury. ${ }^{12}$ This may be of more significance than previously suspected, as a recent Australian study has shown that sporting ankle sprains are associated with persistent long term symptoms in most patients. ${ }^{13}$

It is axiomatic that prevention of such injuries would be desirable, and the first step would be to identify risk factors that may be amenable to intervention. Identifying netball players who are susceptible to injury may allow preventive and treatment efforts to be better focused. Potential interventions could include specific preseason training, targeted exercises, ${ }^{14}$ and prophylactic use of protective equipment, such as ankle guards, strapping, and orthotics. In the event of injury, recognition of hypermobility may result in specific treatment strategies and targeted physiotherapy. ${ }^{15} 16$
Against this background, the aim of this study is to investigate the association between joint mobility and injuries in netball players. The null hypothesis is that hypermobility is not associated with an increased incidence of injuries in junior netball players.

\section{METHOD \\ Setting}

In New South Wales, Australia, netball is organised into a series of regional associations involving a number of clubs who compete at the same complex of multiple netball courts each weekend. Each club fields teams classified by age and standard. The Parramatta-Auburn association comprises a senior and junior league. The junior league (ages 6-16) comprises 13 clubs who play at a single facility of 17 courts. Games are organised on a schedule throughout the day with teams of similar age groups playing at the same time. The New South Wales netball season runs from late March to early September and consists of 15 weekly rounds. This study was conducted during rounds one and two. The study was approved by the Concord Repatriation General Hospital human research ethics committee.

\section{Subjects}

Eligible participants were netball players between the age of 6 and 16 years. Although a random selection of participants from about 420 eligible players would have been desirable, this was not practical. Instead, a convenience sample was assembled of all players who could be approached by the research team in the short time period after each set of concurrent games and whose parent or guardian could give consent.

\section{Questionnaire administration and determination of hypermobility score}

Informed consent was obtained from each subject and their parent. Each participant then completed a self administered 


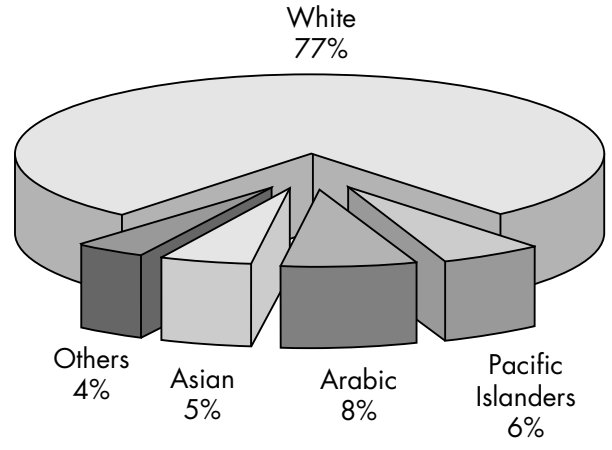

Figure 1 Proportions of different ethnic groups in study sample.

questionnaire on player profile, netball injuries (whenever incurred), non-netball sporting injuries, treatment, and protective equipment used while playing netball. An injury was defined as trauma to a specified body part causing the participant to cease play and miss at least one game. Player profile information included data on the player's age, ethnic background, years of netball played, position on the court, and the number of games and practices a week.

After completion of the questionnaire, but without any reference to it by the assessing clinician, the subject was assessed for hypermobility using the validated Beighton index for hypermobility. Previous studies have shown that the range of movement of a joint can be different before and after a warm up, ${ }^{17}$ therefore, for consistency, all players were assessed at the end of each game. The Beighton index gives an overall composite score of 0-9 and can also be categorised into three groups: 0-2 (not hypermobile); 3-4 (moderately hypermobile); 5-9 (distinctly hypermobile). ${ }^{18}$ The study team consisted of four observers who had received training and standardisation in the Beighton hypermobility index.

\section{Outcome measures and statistical analysis}

The principal outcome measures were the reporting of any injury as a result of netball and the hypermobility score. We classified the Beighton scores into the three categories described above (0-2, 3-4, and 5-9). Statistical analysis was by the $\chi^{2}$ test, with a significance level set at $p=0.05$. Secondary outcomes were non-netball sporting injuries and the use of protective equipment such as ankle guards by the netball players.

Logistic regression was used to further assess the relation between Beighton hypermobility score and the presence of netball injuries by adjusting for potential confounding factors including age, years playing netball, games played a week, and court positions.

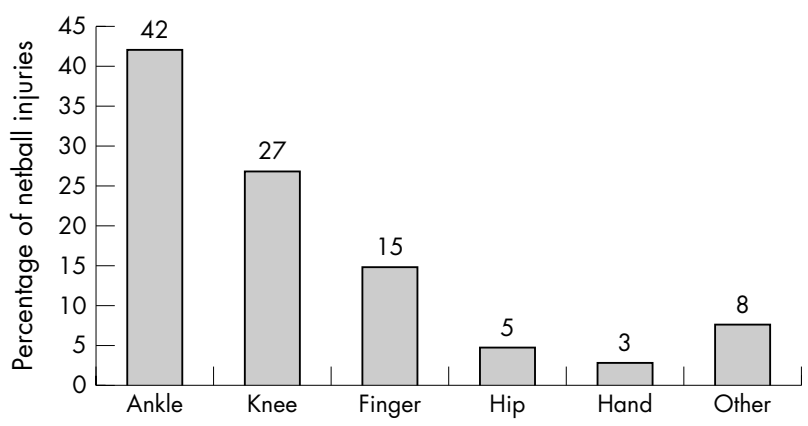

Figure 2 Distribution of site of netball injuries.

\section{RESULTS}

Two hundred netball players between the ages of 6 and 16 (mean (SD) age 11 (2.5)) were recruited. Most of the subjects $(77 \%)$ were white with other races present, reflecting the diverse local population (fig 1). The sample represented an equal distribution of netball positions. Sixty nine $(35 \%)$ of the netball players had sustained some form of injury while playing netball. Forty four $(22 \%)$ had sustained injuries playing sports other than netball. The most common injuries sustained playing netball were ankle $(42 \%)$, knee $(27 \%)$, and finger (15\%) (fig 2).

The mean (SD) Beighton score was 3.99 (2.8). Figure 3 shows the percentage of players who had sustained a netball injury in each hypermobility classification (Beighton group). Of the 70 non-hypermobile, (Beighton score 0-2) players, 15 $(21 \%)$ had sustained netball injuries. In the moderately hypermobile group (Beighton score 3-4), 19 of 51 players (37\%) had sustained netball injuries, but the highest proportion of injured players came from the distinctly hypermobile group, with 34 of $79(43 \%)$ reporting injuries $\left(\chi^{2}\right.$ test; $\left.\mathrm{p}<0.025\right)$.

Fewer injuries were sustained while playing non-netball sports, and the difference between the Beighton groups was not significant (table 1). Thirty nine players wore protective equipment; most of these (78\%) had previously sustained an injury while playing netball. No significant association was found between the different Beighton groups and the use of protective equipment.

Logistic regression analysis showed hypermobility to be an independent risk factor for netball injury (table 2). Netball players with Beighton scores 3-4 were 3.4 times more likely to have been injured ( $\mathrm{p}=0.015)$, and players with Beighton scores 5-9 were 3 times more likely to have been injured $(\mathrm{p}=0.01)$ than subjects with non-hypermobile joints (Beighton score 0-2). For every year of netball played, there was a 1.5 times increase in the netball injury rate. Age, position on court, ethnicity, and number of games a week were not predictors of injury.

\section{DISCUSSION}

This cross sectional study has shown a significant association between clinically assessed joint hypermobility and self reported injury rates, so the null hypothesis is rejected. The proportion of netball players who sustained an injury increased in an incremental fashion with an increase in the Beighton hypermobility score. Before accepting this conclusion, it is necessary to consider the strengths and weaknesses of the study to determine whether there are any biases or other methodological problems that may have distorted the results.

No previous study has looked at hypermobility and injury rates in netball. A strength of this study is that it is reasonably large and representative, involving 200 junior

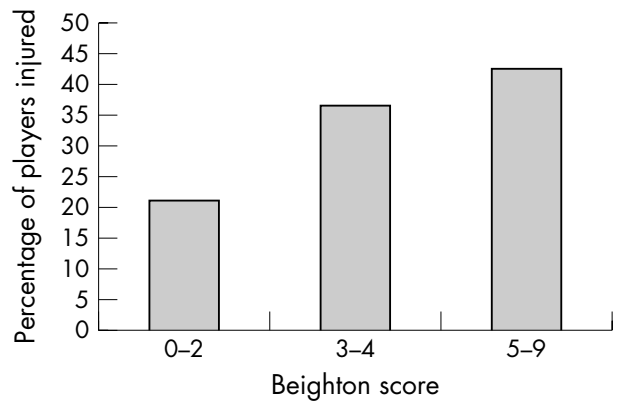

Figure 3 Percentage of players who had sustained a netball injury in each hypermobility classification (Beighton group). 
Table 1 Sporting (non-netball) injuries in each Beighton score group

\begin{tabular}{lllc}
\hline $\begin{array}{l}\text { Beighton } \\
\text { score }\end{array}$ & $\begin{array}{l}\text { No } \\
\text { injured }\end{array}$ & $\begin{array}{l}\% \\
\text { injured }\end{array}$ & Total \\
\hline $0-2$ & 17 & 24 & 70 \\
$3-4$ & 5 & 10 & 51 \\
$5-9$ & 18 & 23 & 79 \\
Total & 40 & 20 & 200 \\
\hline$\chi^{2}$ test $p<0.2$. & & & \\
\hline
\end{tabular}

netball players from a competition of about 420 . Each player was individually examined, and data were gathered by questionnaire completed by the player at the court side. There was no reason to believe that the method of recruitment led to bias by favouring injured over non-injured players or those with or without hypermobility.

Previous studies have focused on injury rates in groups thought to have a high incidence of hypermobility, such as dancers and ballerinas. ${ }^{17}$ This study differs from previous work, in that a population was identified independent of any expectation about their joint mobility.

The 1973 Beighton scoring system was selected as it has been reliably validated in previous studies performed on athletes $^{18}$ and in children ${ }^{4}$ and was designed primarily as an epidemiological tool. The Brighton criteria for benign joint hypermobility syndrome, although using Beighton's scoring system, also includes clinical features unsuitable for an epidemiological study and has not previously been validated in children.

Confounding variables were controlled for in this study by incorporation into a logistic regression analysis. Age, number of years of playing netball, and ethnicity proved not to be confounding factors. Predictably, the number of years of netball played proved to be an independent risk factor for total number of netball injuries. This would reflect a higher total exposure to the potential for injury and provides indirect evidence that our sample and injury assessment tool were reasonable.

The principal weakness of this study is that it is cross sectional and therefore can reveal an association between joint hypermobility and injury rates, but not permit the cause to be determined. We are performing a prospective study to tackle this question. Nevertheless, there seems to be no reason not to accept the findings of this study.

Considering the secondary findings of the study, it is perhaps not surprising that no association was found between hypermobility and non-netball sporting injuries. The overall number of non-netball sporting injuries was lower than netball injuries because netball was the dominant sport of the subjects.

Overall, a third of netball players had previously sustained an injury while playing netball. The most common injuries were to the ankles, knees, and fingers. These results are in accord with previous studies of netball players of all age groups, ${ }^{19}$ but one study of under 15 year old netball players (both male and female) showed a surprisingly small percentage of knee injuries (3\%). ${ }^{12}$ This study, however, was based on presentations to hospital, which may have missed injuries that precluded playing sport but did not necessitate presentation at hospital.

It remains unclear why subjects with hypermobile joints have an increased susceptibility to injury. There is no doubt that there is an increased maximal stretch angle in the hypermobile muscle tendon unit with an enhanced tolerance to passive tension, ${ }^{20}$ but this has not been shown to have a direct link with muscular complications. Patients with hypermobility syndrome have been shown to have impaired joint proprioception in both the knee and finger joints. ${ }^{2122}$ This impaired proprioception may not just account for an increase in acute injuries but may also explain the increased incidence of secondary degenerative osteoarthritis seen in hypermobile joints. ${ }^{23}$ Hypermobile joints have been shown to be less responsive than normal joints to the local anaesthetic effect of lidocaine, suggesting enhanced nociception ${ }^{24}$ and increased pain response in people with hypermobility. This may lead to a reduction in injury threshold or potentially an over-reporting of previous injuries sustained.

The findings of this study have implications for the prevention and management of netball injuries. Identifying hypermobile players could prompt specific training techniques, aimed at stiffening and strengthening muscular support around susceptible joints. The use of strapping and supports to augment mechanical support and proprioception would seem reasonable for susceptible players. These types of interventions have been applied to specific sporting populations in which hypermobility is accepted as a risk factor for injury, notably dancers and ballerinas. ${ }^{25}$ Carefully conducted

\begin{tabular}{|c|c|c|c|c|}
\hline & \multirow[b]{2}{*}{ Odds ratio } & \multicolumn{2}{|c|}{$95 \% \mathrm{Cl}$ for odds ratio } & \multirow[b]{2}{*}{ p Value } \\
\hline & & Lower & Upper & \\
\hline Age & 1.099 & 0.894 & 1.351 & 0.370 \\
\hline Game/week & 0.770 & 0.329 & 1.800 & 0.546 \\
\hline Years of netball & 1.505 & 1.198 & 1.890 & 0.000 \\
\hline Ethnicity & & & & 0.699 \\
\hline Others & 1.000 & & & \\
\hline White & 0.834 & 0.331 & 2.100 & 0.699 \\
\hline Position & & & & 0.304 \\
\hline Goalkeeper & 0.338 & 0.078 & 1.473 & 0.149 \\
\hline Goal defence & 0.572 & 0.129 & 2.524 & 0.460 \\
\hline Wing defence & 0.462 & 0.120 & 1.769 & 0.259 \\
\hline Centre & 1.547 & 0.397 & 6.027 & 0.529 \\
\hline Wing attack & 1.614 & 0.382 & 6.822 & 0.515 \\
\hline Goal attack & 0.434 & 0.080 & 2.350 & 0.333 \\
\hline Goal shooter & 1.032 & 0.303 & 3.508 & 0.960 \\
\hline Beighton score & & & & 0.017 \\
\hline $0-2$ & 1.000 & & & \\
\hline $3-4$ & 3.364 & 1.261 & 8.973 & 0.015 \\
\hline $5-9$ & 2.998 & 1.297 & 6.928 & 0.010 \\
\hline
\end{tabular}




\section{What is already known on this topic}

- The incidence of hypermobility in school children is estimated to be $13-26.5 \%$

- The Beighton hypermobility index is a validated tool of assessment in athletes and children

- Hypermobility is associated with a variety of musculoskeletal complaints including joint subluxation and dislocation

- The relation between hypermobility and childhood sports injuries is uncertain

\section{What this study adds}

- Hypermobility is significantly associated with an increased incidence of injuries in junior netball players

- In female junior netball players, the most common sites of injury are ankle, knee, and finger

clinical trials would seem to be justified in broader sporting populations.

Finally, it is uncertain to what extent these findings can be applied to other sports, but there is no a priori reason to believe that netball is unique in this association. Most field and court sports involve rapid acceleration, deceleration, and directional changes which place considerable forces through articular and periarticular structures. However, further research would seem to be warranted to consider the relation between hypermobility and sports injuries in different age and sex groups.

\section{Authors' affiliations}

R Smith, A K Damodaran, L Barnsley, New South Wales Institute of Sports Medicine, Sydney, Australia

S Swaminathan, Department of Immunology, Concord Hospital, Concord, New South Wales, Australia

R Campbell, University of Sydney, Sydney, NSW, Australia

Competing interests: none declared

\section{REFERENCES}

1 Ansell BM. Hypermobility of joints. Modern Trends Orthop 1972;6:25-39.

2 Biro F, Gewanter HL, Baum J. The hypermobility syndrome. Pediatrics 1983;72:701-6.

3 Arroyo IL, Brewer EJ, Giannini EH. Arthritis/arthralgia and hypermobility of the joints in schoolchildren. J Rheumatol 1988;15:978-80.

4 Van der Giessen LJ, Liekins D, Rutgers KJ. Validation of Beighton score and prevalence of connective tissue signs in 773 Dutch children. J Rheumatol 2001;28:2726-30.

5 Beighton P, Grahame R, Bird H. Hypermobility of joints. New York: SpringerVerlag, 1983.

6 Larsson LG, Baum J, Mudholkar GS. Hypermobility: features and differential incidence between the sexes. Arthritis Rheum 1987;30:1426-30.

7 Kirk JA, Ansell BM, Bywaters EGL. The hypermobility syndrome: musculoskeletal complaints associated with generalized joint hypermobility. Ann Rheum Dis 1967;26:419-25.

8 Mishra MB, Ryan $P$, Atkinson $P$, et al. Extra-articular features of benign hypermobility syndome. Br J Rheumatol 1996;35:861-6.

9 McCormack M, Briggs J, Hakim A, et al. Injury and benign joint hypermobility syndrome in student classical ballet dancers. British Society for Rheumatology XIX Annual General Meeting 23-26 April 2002, Brighton, UK. 41 Supplement 2, 54 .

10 Finsterbush A, Pogrund $\mathrm{H}$. The hypermobility syndrome: musculoskeletal complaints in 100 consecutive cases of generalized joint hypermobility. Clin Orthop 1982;168:124-7.

11 Australian Netball Association. www.netball.asn.au.

12 Routley V. Sports injuries in children: the five most commonly presented sports. Hazard $1991 ; 9: 1-7$

13 Anandacoomarasamy A, Barnsley L. Long term outcomes of inversion ankle injuries. Br J Sports Med 2005;39:e14.

14 Barton LM, Bird HA. Improving pain by the stabilisation of hyperlax joints. J Orthop Rheumatol 1996;9:46-51.

15 Albers DPT, Agnone MMS. Rehabilitation and taping techniques in the athlete: Hallux and first ray problems. Techniques in Foot \& Ankle Surgery 2003;2:61-72.

16 Hardin JA, Voight ML, Blackburn TA, et al. The effects of "decelerated" rehabilitation following anterior cruciate ligament reconstruction on a hyperelastic female adolescent: a case study. J Orthop Sports Phys Ther 1997:26:29-34.

17 Bird HA. Rheumatological aspects of dance. J Rheumatol 2004:31:12-13.

18 Boyle KL, Witt P, Riegger-Krugh C. Intra-rater and inter-rater reliability of the Beighton and Horan joint mobility index. J Athl Train 2003;38:281-5.

19 Egger G. Sports injuries in Australia. Causes, costs and prevention. A report to the National Better Health Program. Sydney: Centre for Health Promotion \& Research, October, 1990

20 Magnusson SP, Julsgaard C, Aagaard P, et al. Viscoelastic properties and flexibility of the human muscle-tendon unit in benign joint hypermobility syndrome. J Rheumatol 2001;28:2720-5.

21 Mallik AK, Ferrell WR, McDonald AG, et al. Impaired proprioceptive acuity at the proximal interphalangeal joint in patients with the hypermobility syndrome. Br J Rheumatol 1994;33:631-7.

22 Hall MG, Ferrell WR, Sturrock RD, et al. The effect of the hypermobility syndrome on knee joint proprioception. Br J Rheumatol 1995:34:121-5.

23 Jonsson H, Valtysdottir ST, Kjartansson O, et al. Hypermobility associated with osteoarthritis of the thumb base: a clinical and radiological subset of a hand osteoarthritis. Ann Rheum Dis 1996;55:540-3.

24 Arendt-Nielson L, Kaaland P, Bjerring P, et al. Insufficient effect of local analgesics in Ehlers-Danlos type III patients (connective tissue disorder). Acta Anaesthesiol Scand 1990;34:358-61.

25 Howse J. Dance technique and injury prevention, 3rd ed. London: A \& C Black Ltd, 2000. 